\section{Relationship between Texture and Cell Wall Polysaccharides of Fruit Flesh in Various Species of Citrus}

\author{
Noboru Muramatsu and Toshio Takahara \\ Kuchinotsu Branch, Fruit Tree Research Station, Ministry of Agriculture, \\ Forestry and Fisheries, Nagasaki 859-25, Japan
}

Kiyohide Kojima

Faculty of Agriculture, Kyoto Prefecture University, Shimogamo-hangi, Sakyo Kyoto 606, Japan

\section{Tatsushi Ogata}

Kuchinotsu Branch, Fruit Tree Research Station, Ministry of Agriculture, Forestry and Fisheries, Nagasaki 859-25, Japan

Additional index words. firmness, postharvest, neutral sugars, uronic acid

\begin{abstract}
Various species and cultivars of citrus were studied to determine the relationship between texture and cell wall polysaccharide content of fruit flesh. Among those tested cultivars, navel orange (Citrus sinensis Osbeck) and hassaku (C. hassaku Hort. ex Tanaka) were firmest, 'Fukuhara orange' $(C$. sinensis Osbeck) was intermediate, and satsuma mandarin (C. unshiu Marc.) was softest. There was a 3-fold difference in firmness among the 12 citrus cultigens measured. Cohesiveness values ranged from 0.30 to 0.49 and were not correlated with fruit firmness. Sugar content in each cell wall fraction was highest in the water and EDTA fractions, followed by the hemicellulose fraction, and was lowest in the cellulose fraction. Correlation coefficients between firmness and sugar content ranged from 0.69 to 0.88 and were highest in the cellulose fraction. This study suggests that firmness of fruit flesh among the cultigens is influenced by cell wall polysaccharide composition. Chemical name used: ethylenediaminetetraacetic acid (EDTA).
\end{abstract}

Firmness is one of the most important characteristics in evaluating the degree of maturity in various vegetables and fruit. Inheritance of firmness also has been studied in some crops where firmness differs among species and cultivars (Al-Falluji et al., 1982; Brown and Bourne, 1988). Citrus fruit flesh generally is not as firm as that of other fruit, because of juice sacs. However, firmness is an important characteristic in citrus because the firmness of fruit flesh influences the mouth feel of citrus.

Changes in chemical composition during fruit softening occur in various fruit. Soda et al. (1987) suggested that loss of molecular weight of hemicellulose is involved in fruit softening and textural alteration during ripening of kiwifruit [Actinidia deliciosa (A.Chev.) C.F. Liang et R. Ferguson]. Huber (1983) reported that fruit softening could be attributed to the dissolution of cell wall components, particularly polyuronide. In citrus, chemical analysis and microscopic observation of the citrus cell wall revealed the involve-

Received for publication 20 Oct. 1995. Accepted for publication 7 Nov. 1995. Contribution no. D-126 of the Fruit Tree Research Station. The cost of publishing this paper was defrayed in part by the payment of page charges. Under postal regulations, this paper therefore must be hereby marked advertisement solely to indicate this fact.
Plant materials. Medium-sized citrus fruit of 12 cultigens of Citrus (Table 1) were harvested from Jan. to Mar. 1994 at the Kuchinotsu Branch, Fruit Tree Research Station. At harvest and measurement date, each cultigen was mature and edible without storage.

A 2-cm-thick slice was cut horizontally at the equator for each sample fruit and then vertically cut into halves. Half of the samples were used for texture measurement by a rheometer as described below, and the other half were stored at $-72 \mathrm{C}$ to measure cell wall polysaccharides after removal of the segment membrane.

Texture measurement. Textural properties of fruit flesh were measured with a rheometer (RE-3305; YAMADENCo., Tokyo) equipped with a 5-mm-diameter cylindrical probe. Rheometer settings were 1) texture measurement mode; 2) crosshead speed, $0.5 \mathrm{~mm} \cdot \mathrm{s}^{-1}$; and 3 ) compression depth, $4 \mathrm{~mm}$. The testing machine was connected to a personal computer (PC-9801m; NEC, Tokyo) that calculated firmness and cohesiveness from the data for the first and second compressions. Firmness, expressed as Newtons per square meter, was the maximum stress of the first compression. Cohesiveness was the ratio of the area, in arbitrary units, under the second peak (S2) and the area under the first peak (S1). The area under each peak is the integral of stress over deformation and, therefore, represents the work done in each compression. This value is a direct function of the work needed to overcome the internal bonds of the sample. Five fruit were used from each cultivar, and each fruit was measured twice.

Cell wall fractionation. Cell wall fractions were extracted by the method suggested by Wakabayashi et al. (1990). Juice vesicles were homogenized with a 5-fold volume of $100 \%$ methanol and centrifuged at $1000 \times g$ for 10 min. The supernatant was discarded, then $80 \%$ ethyl-alcohol was added to the pellet, and the samples were boiled for $10 \mathrm{~min}$ followed by centrifugation. The residue was washed three times with $100 \%$ acetone and then with a 1 methanol : 1 chloroform (v/v) mixture. The washed residue was dried at $40 \mathrm{C}$. The water fraction was extracted with deionized water for $10 \mathrm{~min}$ at $95 \mathrm{C}$. The residue was washed

Table 1. Difference in texture characteristics among 12 cultigens of citrus.

\begin{tabular}{|c|c|c|}
\hline Cultigen & $\begin{array}{c}\text { Firmness } \\
\left(10^{5} \mathrm{~N} \cdot \mathrm{m}^{-2}\right)\end{array}$ & Cohesiveness \\
\hline Yoshida navel (Citrus sinensis Osbeck) & $1.79 \mathrm{a}^{\mathrm{z}}$ & $0.42 \mathrm{~b}$ \\
\hline Hassaku (C. hassaku Hort. ex Tanaka) & $1.76 \mathrm{a}$ & $0.34 \mathrm{c}-\mathrm{e}$ \\
\hline Hirado buntan (C. grandis Osbeck) & $1.57 \mathrm{~b}$ & $0.31 \mathrm{~d}-\mathrm{f}$ \\
\hline Kawano-Natsudaidai (C. natsudaidai Hayata) & $1.46 \mathrm{bc}$ & $0.36 \mathrm{~cd}$ \\
\hline Yoshida ponkan (C. reticulata Blanco) & $1.36 \mathrm{c}$ & $0.38 \mathrm{bc}$ \\
\hline Fukuhara orange (C. sinensis Osbeck) & $1.20 \mathrm{~d}$ & $0.40 \mathrm{bc}$ \\
\hline Sanbokan (C. sulcata Hort. ex Tanaka) & $0.87 \mathrm{e}$ & $0.37 \mathrm{~b}-\mathrm{d}$ \\
\hline Miyauchi iyo (C. iyo Hort. ex Tanaka) & $0.64 \mathrm{f}$ & $0.49 \mathrm{a}$ \\
\hline Hyuganatsu (C. tamurana Hort. ex Tanaka) & $0.62 \mathrm{f}$ & $0.32 \mathrm{ef}$ \\
\hline Kiyomi (C. unshiu Marc. x C. sinensis Osbeck) & $0.58 \mathrm{f}$ & $0.48 \mathrm{a}$ \\
\hline Seminole (C. paradisi Macf. $\times$ C. reticulata Blanco) & $0.57 \mathrm{f}$ & 0.30 ef \\
\hline Satsuma mandarin (Aoshima) (C. unshiu Marc.) & $0.50 \mathrm{f}$ & $0.40 \mathrm{bc}$ \\
\hline $\operatorname{LSD}_{0.05}$ & 0.15 & 0.06 \\
\hline
\end{tabular}

${ }^{2}$ Mean separation within columns by least significant difference at $P \leq 0.05$. 
twice with distilled water, and after centrifuging again, the supernatant was added to the water fraction. The washed residue then was treated with 2 units porcine pancreatic $\alpha$ amylase (type 1-A; Sigma, St. Louis)/ml in $100 \mathrm{~mm}$ sodium-acetate buffer ( $\mathrm{pH} 6.5)$ for $2 \mathrm{~h}$ at $37 \mathrm{C}$, then washed again with deionized water.

The EDTA fraction was extracted three times from the cell wall by treatment with 50 mM EDTA in 50 mm sodium-phosphate buffer (pH 6.8) for $15 \mathrm{~min}$ at 95C. Hemicellulose was extracted with $17.5 \%(\mathrm{w} / \mathrm{v}) \mathrm{NaOH}$, containing $0.02 \% \mathrm{NaBH}_{4}$, for $18 \mathrm{~h}$. Again, the residue was washed with $4 \%$ acetic acid, then acetone was added, and it was dried at 40C overnight. The residue was dissolved in $72 \% \mathrm{H}_{2} \mathrm{SO}_{4}$. One hour later, water was added, and after separation through a glass filter, the solvent was regarded as the cellulose fraction. Neutral sugar and uronic acid contents in each fraction were calculated by the phenol-sulfuric acid (Dubois et al., 1956) and the calvazol methods (Galambos, 1967), respectively.

\section{Results and Discussion}

A representative example (Miyauchi iyo) of the relationship between deformation and stress in citrus flesh is shown in Fig. 1. The curve should be read from left to right, peak 1 being the first, and peak 2 the second compression. Although Szczesniak (1963) suggested that firmness, cohesiveness, and adhesiveness could be calculated from the curve, adhesiveness, which is defined as the work necessary to pull the probe from the sample, was not detected in our measurement. Since the stress increased as a sample was compressed, the yield point also was not found clearly.

Friedman et al. (1963) measured the texture of several processed foods by texturometer and showed that in each food there was a characteristic relationship between stress and deformation. In our measurement of citrus fruit, the curves of stress and deformation were similar to those of agricultural products measured by Mudahar and Jen (1991) in which adhesiveness was not detected. In our measurement, however, the yield point, which they noted, was not found clearly. Since adhesiveness was absent in the flesh of citrus fruit firmness and cohesiveness were evaluated. Firmness of fruit flesh ranged from 0.50 to $1.79 \times 10^{5} \mathrm{~N} \cdot \mathrm{m}^{-2}$ among the 12 cultigens (Table 1). Navel orange and hassaku were firmest, 'Fukuhara orange' was intermediate, and satsuma mandarin (Aoshima) was softest. The cultivar with the highest firmness value was three times that of the one with the lowest value. Cohesiveness varied from 0.30 to 0.49 and was not correlated with fruit firmness.

Sugar content in the cell wall fractions also varied among citrus cultigens. Total sugar content, composed of neutral sugars and uronic acid, was highest in the water and EDTA fractions, followed by the cellulose fraction, and was lowest in the hemicellulose fraction (Fig. 2A-D). Uronic acid was highest in the EDTA fraction followed by the water fraction, and only trace amounts were present in the hemicellulose and cellulose fractions.

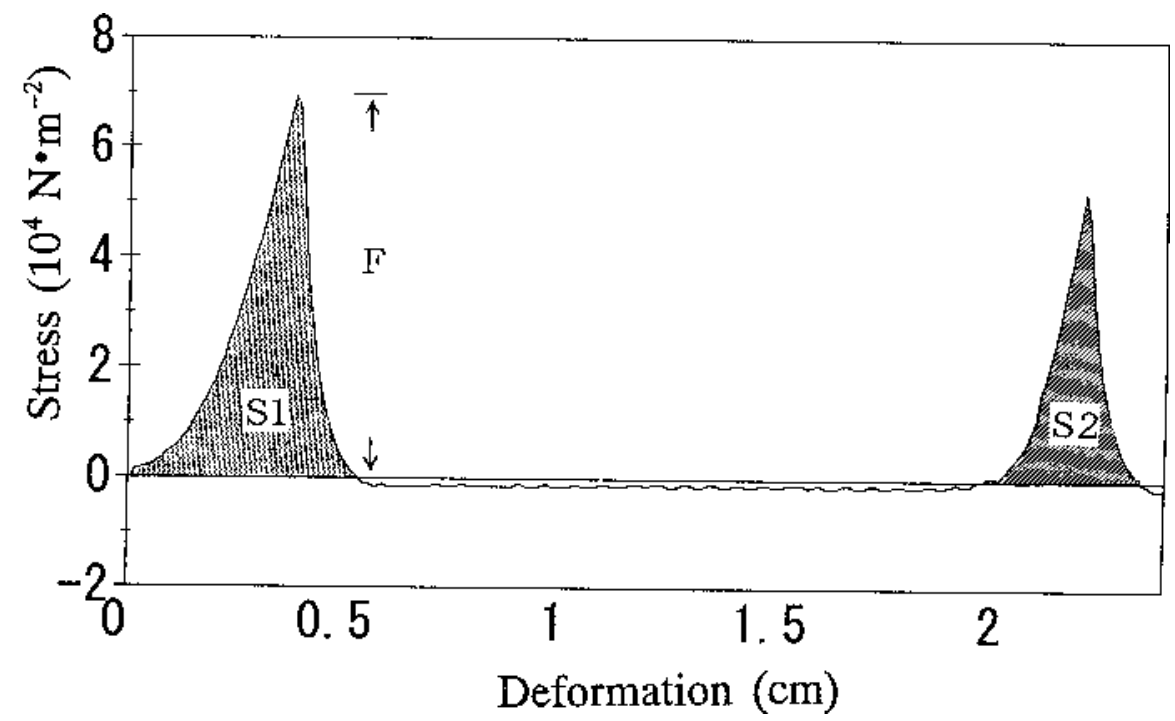

Fig. 1. Relationship between stress and deformation of citrus fruit flesh. Firmness (F) is defined as the maximum stress in compressing a sample $4 \mathrm{~mm}$. Cohesiveness is the ratio of the area under the first peak (S1) to the area under the second peak (S2).
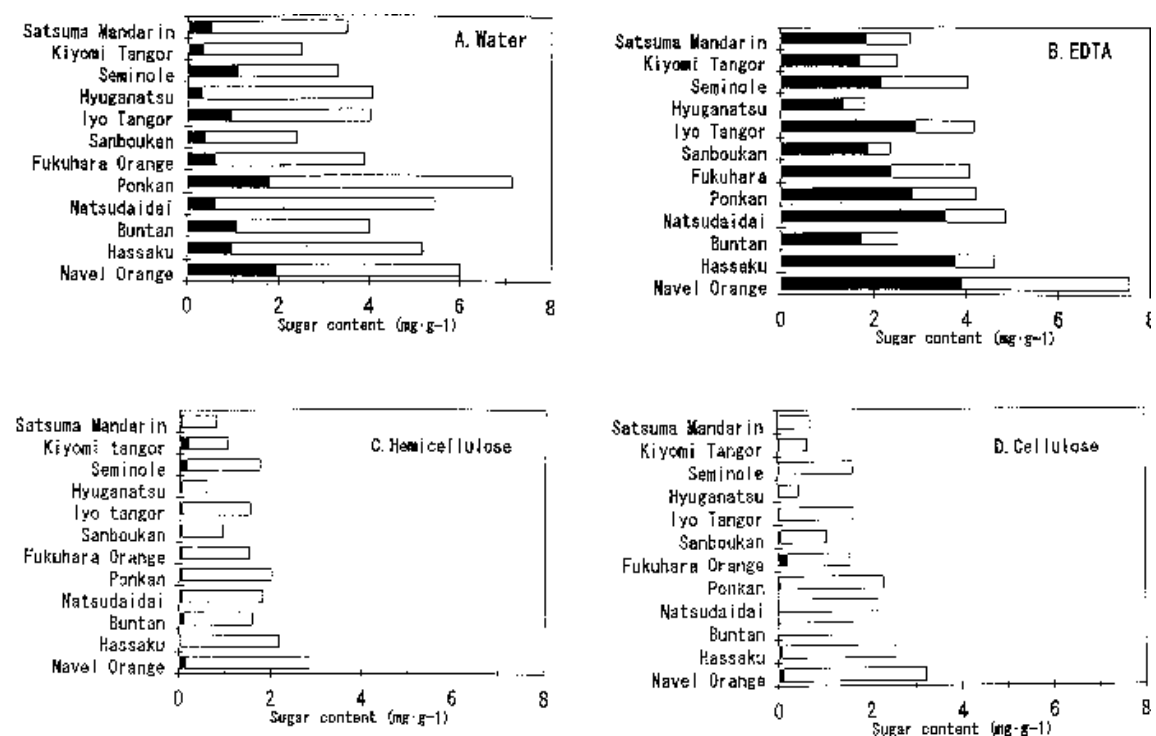

Fig. 2. Sugar composition of various fractions of citrus fruit cultivars: (A) water, (B) EDTA, (C) hemicellulose, and (D) cellulose. $\square$ and $\boldsymbol{\square}$ indicate neutral sugar and uronic acid, respectively. Sugar contents show milligrams per gram of fresh weight of fruit flesh.

In most cultivars, the proportion of total sugar in water was $30 \%$ to $40 \%$, in EDTA $34 \%$ to $39 \%$, in hemicellulose $10 \%$ to $17 \%$, and in cellulose $7 \%$ to $15 \%$. However, in ponkan, hyuganatsu, and satsuma mandarin, the proportion of total sugar in the water fraction was higher, while being lower in other fractions compared to other cultivars. Compared to other fruit and vegetables (Mitcham et al., 1989; Yamaki et al., 1983), our data suggested that the proportion of sugar in the water and EDTA fractions was extremely high and was low in the hemicellulose and cellulose fractions.

Correlation between firmness and sugar content ranged from 0.690 to 0.877 and was strongest in the cellulose fraction and lowest in the water fraction (Fig. 3A-D). Thus, firmness of fruit flesh appeared to be governed by the cell wall polysaccharide content. How- ever, cohesiveness was not correlated with polysaccharide composition.

In summary, firmness and cohesiveness can be used to describe the texture of citrus fruit flesh. Large differences in firmness and cohesiveness among citrus cultivars were found. Additionally, firmness of fruit flesh among the cultivars is influenced by cell wall polysaccharide composition. These data will be helpful in analyzing the heredity of flesh in citrus fruit.

\section{Literature Cited}

Al-Falluji, R.A., D.H. Trinklein, and V.N. Lambeth 1982. Inheritance of pericarp firmness in tomato by generation mean analysis. HortScience 17:763-764

Brown, S.K. and M.C. Bourne. 1988. Assessment of components of fruit firmness in selected sweet 

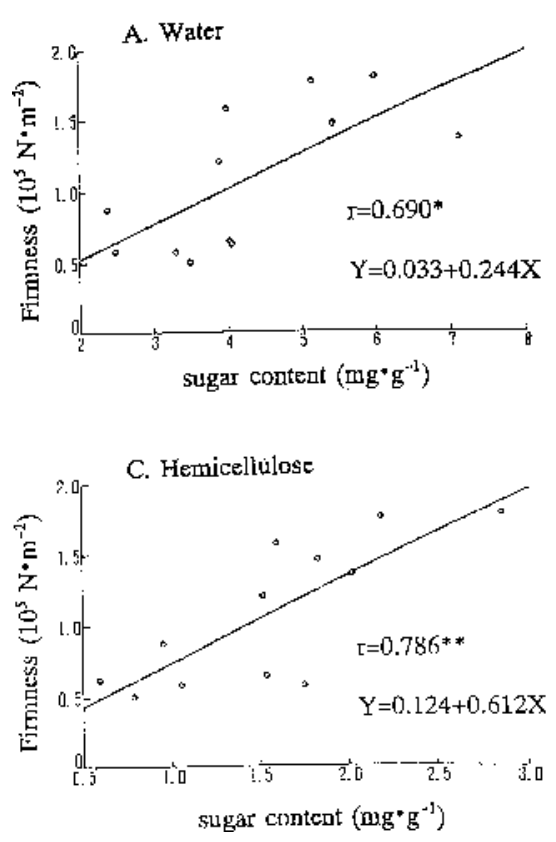
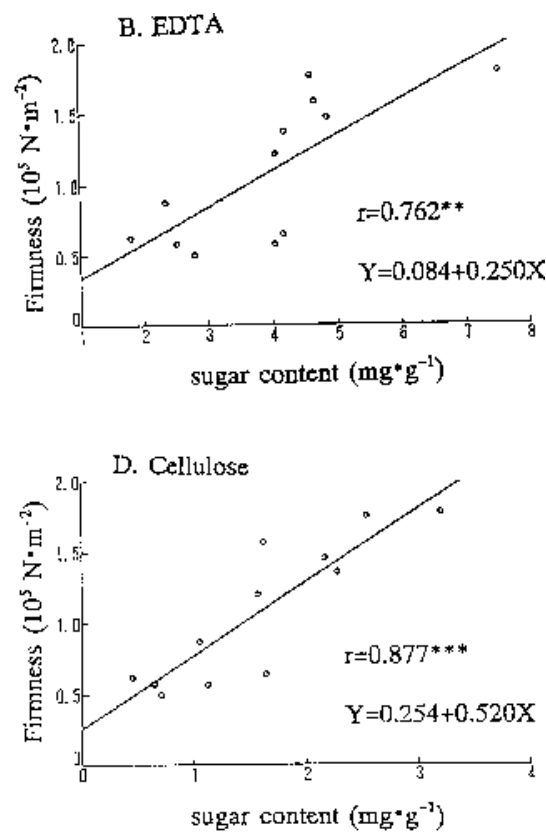

Fig. 3. Relationship between sugar content and firmness of citrus fruit for various fractions: (A) water, (B) EDTA, $(\mathbf{C})$ hemicellulose, and (D) cellulose. ${ }^{* * * * * * *}$ Significance at $P \leq 0.05,0.01$, or 0.001 , respectively, by $t$ test.

cherry genotypes. HortScience 23:902-904.

Dubois, M., K.A. Gilles, J.K. Hamilton, P.A. Rebers, and F. Smith. 1956. Colorimetric method for determination of sugar and related substances. Anal. Chem. 28:350-356.
Friedman, H.H., J.E. Whitney, and A.S. Szczesniak. 1963. The texturometer-A new instrument for objective texture measurement. J. Food Sci. 28:390-396.

Galambos, J.T. 1967. The reaction of carbazole with carbohydrate 1. Effect of borate and sulfate on the carbazole color of sugars. Anal. Biochem. 19:119-132.

Goto, A. and C. Araki. 1983. Chemical composition and internal anatomy of the gelated and granulated juice sacs of Sanbokan fruit. J. Jpn. Soc. Hort. Sci. 52:316-324.

Huber, D.J. 1983. The role of cell wall hydrolases in fruit softening. Hort. Rev. 5:169-219.

Mitcham E.J., K.C. Gross, and T.J. Ng. 1989. Tomato fruit cell wall synthesis during development and senescence. In vivo radiolabeling of wall fractions using $\left[{ }^{14} \mathrm{C}\right]$ sucrose. Plant Physiol. 89:477-481.

Mudahar, G.S. and J.J. Jen. 1991. Texture of raw and canned Jicama and Chinese water chestnut. J. Food Sci. 56:977-980.

Shomer, I., E. Chalutz, R. Vasiliverr, E. Lomaniec, and M. Berman. 1989. Sclerification of juice sacs in pummelo fruit. Can. J. Bot. 67:625632.

Soda, I., T. Hasegawa, and T. Suzuki. 1987. Changes in hemicellulose during after ripening of kiwi fruit. J. Agr. Sci. 31:261-264.

Szczesniak, A.S. 1963. Objective measurements of food texture. J. Food Sci. 28:410-420.

Wakabayashi, K., N. Sakurai, and S. Kuraishi. 1990. Sugar component and molecular weight distribution of cell wall polysaccharide in outer and inner tissues from segment of dark grown squash hypocotyls. Plant Physiol. 93:998-1004.

Yamaki, S., Y. Sato, and Y. Machida. 1983. Characteristics of cell wall polysaccharides and their degrading enzyme activities in mealy fruit and "Ishinashi" fruit of Japanese pear (Pyrus serotina Rehder var. culta Rehder). J. Jpn. Soc. Hort. Sci. 52:123-134. 